\title{
Assessment of Knowledge with Regard to Cardiovascular Disease Risk Factors among College Students Using Heart Disease Fact Questionnaire
}

\author{
Seshagiri Rao Yeluri ${ }^{1}$, Himavathy Kodandarao Gara ${ }^{2}$, Dharma Rao Vanamali ${ }^{3}$ \\ 1,3 Department of General Medicine, Gayatri Vidya Parishad Institute of Healthcare \& Medical Technology, \\ Visakhapatnam, Andhra Pradesh, India. ${ }^{2}$ Department of Physiology, Gayatri Vidya Parishad Institute of \\ Healthcare \& Medical Technology, Visakhapatnam, Andhra Pradesh, India.
}

ABSTRACT

\section{BACKGROUND}

Acquisition and accumulation of cardiovascular risk factors is substantially influenced by an individual's health-seeking behaviour which in turn depends on his knowledge and practices. We wanted to estimate the current awareness and knowledge of cardiovascular disease (CVD) among young college students.

\section{METHODS}

This cross-sectional study involved 1122 participants who filled the Heart Disease Fact Questionnaire (HDFQ) to assess the knowledge about risk factors for CVD, diabetes CVD link, and measures to reduce risk for CVD. Scores of 'less than 50', 'between 51 to 70' and 'more than 70' were rated as 'poor', 'moderate' and 'good' respectively. Quantitative data was computed as mean and standard deviation (SD) and was analysed by independent- $t$ test. All categorical variables were expressed as frequency $(\mathrm{N})$ and percentages (\%) and were analysed using chi-square test. Statistical significance for all analyses was defined as $\mathrm{P}<0.05$.

\section{RESULTS}

Out of 1122 students, $54.19 \%(\mathrm{~N}=608)$ were females. The mean age of the participants was $19.51 \pm 1.238$ years. The mean HDFQ score of total participants was $60.26 \pm 17.20$ with no gender-based differences. $23.88 \%, 44.3 \%$ and $31.82 \%$ of participants had scores graded as poor, moderate and good respectively. The major risk factors for CVD identified by participants were smoking (85.3\%), high blood pressure (85.83\%), high cholesterol (81.28\%), being overweight (80.57\%), aging (64.97\%), and diabetes (63.19\%). $84.5 \%$ participants agreed that regular physical activity would reduce chances of CVD. The correct response rate for high density lipoprotein (HDL) and low-density lipoprotein (LDL) cholesterol were $41.8 \%$ and $40.91 \%$ respectively. The least correct responses were obtained regarding role of age, gender, genetics and family history in CVD (43.13\%), followed by the role of diet and cholesterol levels (48.57\%). The highest correct responses were obtained for risk factors for CVD (77.09\%), followed by role of exercise (72.10\%).

\section{CONCLUSIONS}

The correct response rate for HDFQ was $60 \%$ with no gender-based difference. Participants had almost $80 \%$ knowledge about modifiable risk factors and $<50 \%$ knowledge about role of non-modifiable risk factors and role of diet and cholesterol in pathogenesis of CVD. Bridging the knowledge gap through educational interventions can improve awareness about CVD prevention and management among young population.

\section{KEY WORDS}

Cardiovascular Disease, Awareness, Knowledge, Questionnaire, Risk Factors
Corresponding Author: Dr. Vanamali Dharma Rao, Professor,

Department of General Medicine, Gayatri Vidya Parishad Institute of Healthcare \& Medical Technology, Visakhapatnam, Andhra Pradesh, India. E-mail:vdrao1@gmail.com

DOI: $10.14260 /$ jemds $/ 2021 / 78$

How to Cite This Article:

Yeluri SR, Gara HK, Vanamali DR. Assessment of knowledge with regard to cardiovascular disease risk factors among college students using heart disease fact questionnaire. J Evolution Med Dent Sci 2021;10(06):347-351, DOI: $10.14260 / \mathrm{jemds} / 2021 / 78$

Submission 02-10-2020,

Peer Review 07-12-2020,

Acceptance 15-12-2020,

Published 08-02-2021.

Copyright (c) 2021 Seshagiri Rao Yeluri et al. This is an open access article distributed under Creative Commons Attribution License [Attribution 4.0 International (CC BY 4.0)] 


\section{BACKGROUND}

The surge in cardiovascular disease among Indian population in past two decades has accounted for 1 in 4 deaths making CVD as the leading cause of mortality and morbidity in India. ${ }^{1,2}$ The term 'CVD' comprises the constellation of coronary heart disease, stroke, peripheral vascular disease and heart failure. The INTERHEART study has highlighted 53 years as the median age for the first presentation of acute myocardial infarction (MI) among the South Asian population as compared to 63 years in other population around the world. ${ }^{3}$ The occurrence of CVD a decade earlier and 5 - $10 \% \mathrm{MI}$ in age less than 40 years among Indians is ominous and has resulted in substantial loss of productive life-years. ${ }^{4,5}$

The drift from infectious diseases towards noncommunicable diseases (NCD) is attributable to the constellation of genetics, metabolic risks, sedentary lifestyle, socioeconomic and psychological stress, fewer intakes of vegetables and fruits and increased consumption of fast foods, tobacco and alcohol. 5 This unhealthy epidemiological transition is now prevalent in all socioeconomic strata and both urban and rural areas despite the demographic heterogeneity of prevalence of risk factors. ${ }^{6}$ The Framingham Heart study has suggested the risk factors do not act in isolation and minor abnormalities in several risk factors may act synergistically to effectuate a high risk of disease. ${ }^{7}$ Hence, it is crucial to screen population for socio-economic inequalities, literacy level, cultural diversity and presence of risk factors (modifiable and non-modifiable). ${ }^{8}$ The National Health Policy of 2017 has outlined to achieve $25 \%$ reduction in premature mortality from CVD and other NCDs coupled with screening of $80 \%$ of known hypertensive and diabetic individuals to maintain, controlled disease status by 2025.9

Coexisting ailments like hypertension, diabetes mellitus, dyslipidaemia, etc; further accelerate CVD progression, which accounts for enormous health expenditure on household as well as national economy. ${ }^{10}$ The Global Cardiovascular Disease Taskforce has stressed on implementation of cost-effective population-wide strategies to reduce the risk of premature NCD death by $25 \%$ by 2025.11 To contain the CVD associated morbidity and premature mortality, it is essential to design and adopt health policies based on population attributable factors and risk factors with profound impact. Prevention is an effective cost-saving intervention to reduce CVD burden which can be primordial: population-based, primary: individualbased and secondary: patient-based.12 Primordial prevention starts early in life as it refers to avoid development of risk factors. Primary prevention targets treating risk factors through education, counseling and consultation so as to prevent disease manifestation. Secondary prevention comprises of evidence-based screening programs and preventive drug therapies to improve patient outcome.

The atherosclerotic vascular changes may initiate in childhood as fatty streaks in the intima of arteries. ${ }^{13}$ Progression to a significant clinical event is influenced by presence of risk factors and co-existing diseases. Health promotion empowers people to achieve optimal health by adopting lifestyle modifications, which are facilitated through amalgamation of knowledge, commitment and healthy practices. $^{14}$ Also, individual's perception of susceptibility tends to enhance his prevention-seeking behaviour.
Behaviours laid down at early life track their path into adulthood and set trajectories of lifelong health. Early adoption and advocacy of heart-healthy lifestyle by youngsters can decelerate acquisition and accumulation of CVD risk. Hence, the purpose of the study was to estimate the current knowledge and awareness of CVD among the young college students.

\section{METHODS}

It is a cross-sectional study conducted from $1^{\text {st }}$ October 2019 to $31^{\text {st }}$ October 2019 among college students in Gayatri Vidya Parishad Engineering College, Visakhapatnam using heart disease fact questionnaire (HDFQ) questionnaire. ${ }^{15}$ The study was initiated after obtaining institutional ethical committee clearance. Informed consent was obtained and confidentiality was assured. The participation in the study was voluntary and no incentives were awarded in return. The participants underwent initial screening for participation. Inclusion criteria were (1) age $\geq 18$ years and $\leq 25$ years (2) able to read and understand English. The eligible participants were briefed about the purpose of the study and were asked to fill their questionnaire. Doubts, if any, were assisted. The sociodemographic data contained age and sex.

\section{Sample Size Calculation}

Based on a previous study by Umuerri EM et al., $59 \%$ of participants had poor knowledge and perception of heart disease. ${ }^{16}$ A sample of 372 students was calculated using the online Epi Info software program version 3, based on the following criteria: confidence level of $95 \%$, margin of error of $5 \%$, population proportion of $59 \%$ and population size unlimited.

\section{Heart Disease Fact Questionnaire}

This questionnaire consisting of 25 items was developed by Wagner et al. in English. ${ }^{15}$ It aims to assess the knowledge about risk factors for CVD, diabetes-CVD link, and measures to reduce risk for CVD. It is psychometrically sound instrument with good item difficulty, meaningful construct, and excellent readability with minimal burden to respondents, readable by an average 13-year-old. The internal consistency is 0.77 , as per Kuder-Richardson formula-20, indicating respectable reliability and validity. It can discriminate the groups depending on their educational qualification and knowledge about CVD. It is a useful tool to address knowledge deficits and bring about health behaviour change.

The response for each statement was to be given as "true", "false" or "I don't know". Six of the statements were scored reverse. Each correct response was scored as "1", while each incorrect response or "I don't know" was scored "0". The number of correct responses when multiplied by four yielded the total score, which ranged from " 0 - 100"7. Scores of "less than 50 ', 'between 51 to 70 ' and 'more than 70 ' were rated as 'poor', 'moderate' and 'good' respectively. The 25 items were further categorised for assessment of knowledge in different domains as follows - 


\begin{tabular}{|ccc|}
\hline Sl. No & Area of Knowledge & Item \\
1 & Role of age, gender, genetics and family history & $1,2,3,25$ \\
2 & Risk factors for CVD & $4,6,8,12,16,18$ \\
3 & Role of exercise in prevention & $13,14,15$ \\
4 & $\begin{array}{c}\text { Role of diet and cholesterol levels in CVD } \\
\text { Role of therapeutic measures and lifestyle } \\
\text { intervention for CVD }\end{array}$ & $9,10,11,17,20,22$ \\
\hline & $\begin{array}{c}\text { Table 1. Domains and the Items Included } \\
\text { in Heart Disease Fact Questionnaire }\end{array}$ \\
\hline \multicolumn{3}{|c|}{$\begin{array}{l}\text { The percentages of total correct responses in each domain were } \\
\text { calculated. }\end{array}$} \\
\hline
\end{tabular}

\section{Statistical Analysis}

All the data was organised using Microsoft Excel and was analysed using Statistical Package for Social Sciences (SPSS) version-26. Quantitative data was computed as mean and standard deviation (SD) and independent ' $t$ ' test was utilised to analyse the difference. All categorical variables were expressed as frequency ( $\mathrm{N}$ ) and percentages (\%) and were analysed using chi-square test. Statistical significance for all analyses was defined as $\mathrm{P}<0.05$.

\section{RESULTS}

A total of 1122 college students participated in this survey of whom $54.19 \%(\mathrm{~N}=608)$ were females. The mean age of the participants was $19.51 \pm 1.238$ years, age ranging between 18 to 25 years.

\begin{tabular}{|ccccc|}
\hline & Total & Boys & Girls & P-Value \\
\hline Number (\%) & $\mathbf{1 1 2 2}$ & $514(44.81)$ & $608(54.19)$ & - \\
Mean HDFQ score & $\mathbf{6 0 . 2 6} \pm \mathbf{1 7 . 2 0}$ & $59.87 \pm 17.75$ & $60.58 \pm 16.39$ & $* 0.812$ \\
Score & & & & \\
Poor $(<50)$ & $\mathbf{2 6 8 ( 2 3 . 8 8 )}$ & $128(24.90)$ & $140(23.03)$ & \\
Moderate (51- 70) & $\mathbf{4 9 7}(\mathbf{4 4 . 3})$ & $222(43.19)$ & $275(45.23)$ & $0.713^{* *}$ \\
Good $(>70)$ & $\mathbf{3 5 7}(\mathbf{3 1 . 8 2})$ & $164(31.91)$ & $193(31.74)$ & \\
\hline \multicolumn{5}{c}{ Table 2. HDFQ Scores of Participants } \\
*P-value was estimated using independent 't' test \\
** P-value was calculated using Chi-square test \\
\hline
\end{tabular}

\begin{tabular}{|c|c|c|c|c|}
\hline Sl. No & Question & $\begin{array}{l}\text { True }^{*} \\
\text { N (\%) }\end{array}$ & $\begin{array}{l}\text { False }^{*} \\
\text { N (\%) }\end{array}$ & $\begin{array}{c}\text { I Don't Know* } \\
\text { N (\%) }\end{array}$ \\
\hline 1 & A person always knows when they have heart disease & $216(19.25)$ & $551(49.11)^{\#}$ & $355(31.64)$ \\
\hline 2 & If you have a family history of heart disease, you are at risk for developing heart disease & $477(42.5) \#$ & $386(34.4)$ & $259(23.1)$ \\
\hline 3 & The older a person is, the greater their risk of developing heart disease & $729(64.97)^{\#}$ & $197(17.56)$ & $196(17.47)$ \\
\hline 4 & Smoking is a risk factor for heart disease & $957(85.3)^{\#}$ & $71(6.33)$ & $94(8.37)$ \\
\hline 5 & A person who stops smoking will lower their risk of developing heart disease & $784(69.87)^{\#}$ & $142(12.66)$ & $196(17.47)$ \\
\hline 6 & High blood pressure is a risk factor for heart disease & $963(85.83)^{\#}$ & $64(5.7)$ & $95(8.47)$ \\
\hline 7 & Keeping blood pressure under control will reduce a person's risk for developing heart disease & $929(82.8)^{\#}$ & $71(6.33)$ & $122(10.87)$ \\
\hline 8 & High cholesterol is a risk factor for developing heart disease & $912(81.28)^{\#}$ & $105(9.36)$ & $105(9.36)$ \\
\hline 9 & Eating fatty foods does not affect blood cholesterol levels & $215(19.16)$ & $801(71.4)^{\#}$ & $106(9.44)$ \\
\hline 10 & If your 'good' cholesterol (HDL) is high, you are at risk for heart disease & $131(11.68)$ & $469(41.8)^{\#}$ & $522(46.52)$ \\
\hline 11 & If your 'bad' cholesterol (LDL) is high, you are risk for heart disease & $459(40.91)^{\#}$ & $128(11.41)$ & $535(47.68)$ \\
\hline 12 & Being overweight increases a person's risk for heart disease & $904(80.57)^{\#}$ & $94(8.38)$ & $124(11.05)$ \\
\hline 13 & Regular physical activity will lower a person's chance of getting heart disease & $948(84.5)^{\#}$ & $91(8.11)$ & $83(7.39)$ \\
\hline 14 & Only exercising at a gym or in an exercise class will lower a person's chance of developing heart disease & $303(27)$ & $621(55.35)^{\#}$ & $198(17.65)$ \\
\hline 15 & Walking and gardening are considered exercise that will help lower a person's chance of developing heart disease & $858(76.48)^{\#}$ & $94(8.37)$ & $170(15.15)$ \\
\hline 16 & Diabetes is a risk factor for developing heart disease & $709(63.19)^{\#}$ & $155(13.81)$ & $258(23)$ \\
\hline 17 & High blood sugar puts a strain on the heart & $797(71.04)^{\#}$ & $106(9.44)$ & $219(19.52)$ \\
\hline 18 & $\begin{array}{l}\text { If your blood sugar is high over several months, it can cause your cholesterol level to go up and increase the risk } \\
\text { of heart disease }\end{array}$ & $744(66.31)^{\#}$ & $105(9.36)$ & $273(24.33)$ \\
\hline 19 & $\begin{array}{c}\text { A person who has diabetes can reduce their risk of developing heart disease if they keep their blood sugar levels } \\
\text { under control }\end{array}$ & $649(57.84)^{\#}$ & $188(16.76)$ & $285(25.4)$ \\
\hline 20 & People with diabetes rarely have high cholesterol & $325(28.97)$ & $355(31.64)^{\#}$ & $442(39.39)$ \\
\hline 21 & $\begin{array}{l}\text { If a person has diabetes keeping their cholesterol under control will help to lower their chance of developing } \\
\text { heart disease }\end{array}$ & $729(64.97)^{\#}$ & $121(10.78)$ & $272(24.25)$ \\
\hline 22 & People with diabetes tend to have low HDL cholesterol & $386(34.4)^{\#}$ & $174(15.51)$ & $562(50.09)$ \\
\hline 23 & $\begin{array}{c}\text { Person who has diabetes can reduce their risk of developing heart disease if they keep their blood pressure under } \\
\text { control }\end{array}$ & $705(62.83)^{\#}$ & $152(13.55)$ & $265(23.62)$ \\
\hline 24 & Person who has diabetes can reduce their risk of developing heart disease if they keep their weight under control & $686(61.14)^{\#}$ & $146(13.01)$ & $290(25.85)$ \\
\hline 25 & Men with diabetes have higher risk of heart disease than women with diabetes & $514(45.81)$ & $179(15.95) \#$ & $429(38.24)$ \\
\hline \multicolumn{5}{|c|}{ Table 3. Measures of Heart Disease Knowledge (N = 1122) } \\
\hline . & $\begin{array}{l}\text { ressed as frequency and percentages } \\
\text { ect response to that question }\end{array}$ & & & \\
\hline
\end{tabular}

The mean HDFQ score of total participants was $60.26 \pm$ 17.20. The HDFQ score in both males and females was almost similar with slight difference which had no statistical significance. $23.88 \%, 44.3 \%$ and $31.82 \%$ of participants had scores graded as poor, moderate and good respectively in which males and females had no statistically significant difference.

The major risk factors for CVD identified by participants were smoking (85.3\%), high blood pressure (85.83\%), high cholesterol (81.28\%), being overweight (80.57\%), aging (64.97\%), diabetes (63.19\%) and family history (42.5\%), $84.5 \%$ participants agreed that regular physical activity would reduce chances of CVD. The correct response rate for
HDL and LDL cholesterol were $41.8 \%$ and $40.91 \%$ respectively.

The least correct responses as $15.95 \%, 31.64 \%$ and 34.4 $\%$ were obtained for questions "Men with diabetes have higher risk of heart disease than women with diabetes", "People with diabetes rarely have high cholesterol" and "People with diabetes tend to have low HDL cholesterol" respectively.

\begin{tabular}{|cc|}
\hline Area of Knowledge & Correct Response Rate N (\%) \\
Role of age, gender, genetics and family \\
history & $484(43.13)$ \\
Risk factors for CVD & $865(77.09)$ \\
Role of exercise in prevention & $809(72.1)$ \\
$\begin{array}{c}\text { Role of diet and cholesterol levels in CVD } \\
\text { Role of therapeutic measures \&lifestyle } \\
\text { intervention for CVD }\end{array}$ & $545(48.57)$ \\
\hline Table 4. Response Rate for Knowledge in Different Categories of HDFQ \\
\hline
\end{tabular}


As per Table: 4, the participants gave least correct responses for questions pertaining to role of age, gender, genetics and family history in CVD (43.13\%), followed by role of diet and cholesterol levels (48.57\%). The highest correct responses were obtained for risk factors for CVD (77.09\%), followed by role of exercise $(72.10 \%)$ and therapeutic measures and lifestyle intervention for CVD (66.58 \%).

\section{DISCUSSION}

A comprehensive approach for CVD prevention and management addresses all aspects of individual lifestyles, shared decision-making and estimation of risk for $\mathrm{CVD}^{8}$. Knowledge and perception about risk factors are the primary drivers for population-based primordial prevention and individual-based primary prevention. The present survey aimed to estimate the knowledge regarding risk factors for CVD among young students.

The present study revealed $60 \%$ accuracy rate in HDFQ scores which needs to be addressed. Also, the scores among males and females were almost similar revealing no genderbased difference in knowledge. Sadasivam $\mathrm{K}$ et al. in his study showed knowledge score among medical students was $71.4 \%$, which could be attributed to exposure to medical curriculum and sensitisation towards disease. ${ }^{17}$ Cognizance about risk factors and preventive measures coupled with adherence to pharmacotherapy and lifestyle interventions are the key determinants to alter substantial premature deaths and disabilities associated with CVD. ${ }^{8}$ About $1 / 5^{\text {th }}$ of participants had HDFQ score $<50 \%$ which is of definite concern. Ignorance and misconception may influence the decision-making and effectuate as failure or delayed engagement in health-seeking behaviour.

The present study revealed participants had least knowledge (around $40 \%$ ) regarding role of age, gender and genetics which constitute non-modifiable factors. Owing to these unchangeable traits and predetermined role in pathogenesis of CVD, individuals may nurture inclination towards risky behaviours and develop a fatalistic approach towards health. This attitude could pose threat to his health and well-being. This demands assessment, communication and counselling to motivate individuals towards ideal cardiovascular health. ${ }^{14,16}$

The modifiable risk factors for CVD constitute hypertension, smoking, hyperlipidaemia, diabetes mellitus, obesity, sedentary lifestyle and diet. ${ }^{10}$ The consequential clinical events and premature deaths could be downscaled by lifestyle changes and targeting modifiable risk factors. ${ }^{16}$ In the present study, more than $80 \%$ of participants identified smoking, hypertension, high cholesterol, being overweight as risk factors for CVD. Their accuracy in this knowledge domain was highest $(77.08 \%)$, thus reflected their good awareness. More than $80 \%$ participants were confident that regular physical activity would lower risk for CVD. Sattelmair J et al. in their meta-analysis concluded that aerobic physical activity lowered CVD risk. ${ }^{18}$ Around $70 \%$ showed positive attitude towards exercise and importance of therapeutic measures and lifestyle modifications for CVD. Appropriate management of hypertension, diabetes and hyperlipidaemia has been demonstrated to improve patient's outcome with CVD. ${ }^{8}$

In the present study, though dyslipidaemia was identified as risk factor by about $80 \%$ participants, the correct response rates for HDL and LDL cholesterol were about $40 \%$, thus, reflecting inadequate knowledge about the role of HDL and LDL cholesterol in pathophysiology of CVD. Also, the accuracy for knowledge regarding diet and cholesterol was around 50 $\%$ which is suboptimal.

The knowledge gap is further precipitated by individual food choice, social and cultural norms, economic factors, palatability and marketing of low-nutritious food 6 . A sustainable healthy eating pattern can be achieved by nutrition education, appropriate food marketing and awareness about point-of-purchase nutrition labelling. ${ }^{19}$ The Food Safety and Standards Authority of India drafted guidelines in 2019 for converting schools into Eat Right School for promoting safe and healthy food consumption among school children and limiting availability of food items high in sugar, salt and fats. ${ }^{20}$ This dietary and nutritional intervention would encourage health promotion and disease prevention among adolescents.

Holistic approach embracing identification of socioeconomic determinants of health, early detection of risk factors, population-based surveillance, and health promotion activities is needed. It should be coupled with political leadership and CVD monitoring systems to frame and formulate primordial, primary and secondary prevention and policies to reduce strain both on healthcare sector as well as country's economy. ${ }^{11,12}$

\section{CONCLUSIONS}

The correct response rate for HDFQ was $60 \%$ with no genderbased difference and is definitely a call for concern. The participants had almost $80 \%$ knowledge about risk factors for CVD and $<50 \%$ knowledge about role of age, genetics, diet and cholesterol in pathogenesis of CVD.

To tackle CVD burden and bridge the knowledge gap, it is essential to develop educational interventions to facilitate risk prediction and risk stratification approach at individual and community level. Implementation of heart-healthy behaviour at early ages can help to postpone CVD related clinical event, lower case fatality rate and reduce healthcare costs.

\section{Limitations}

It was a cross-sectional study with limited socio-demographic information. It involved students with fluency in English, hence, findings can't be generalisable. However, the large sample size is the strength of the study.

Data sharing statement provided by the authors is available with the full text of this article at jemds.com.

Financial or other competing interests: None.

Disclosure forms provided by the authors are available with the full text of this article at jemds.com.

We would like to express our deep sense of gratitude to Dr. P. Somaraju, Chairman of GVP IHC \& MT for his support and encouragement for this study. We would also like to extend our gratitude to Prof Dr. D.V.V.S. Rama Murthy, the Dean; Prof Dr. B. 
Narasinga Rao, HOD of Dept of Microbiology, Prof Dr. A. Rangarao, Professor in Dept. of Surgery and Prof. Dr. N. Ramakrishna, HOD of Dept. of Biochemistry for their help towards the study project. Also, we would like to thank the students for their interest and participation.

\section{REFERENCES}

[1] India State-Level Disease Burden Initiative CVD Collaborators. The changing patterns of cardiovascular diseases and their risk factors in the states of India: the Global Burden of Disease Study 1990-2016. Lancet Glob Health 2018;6(12):E1339-51.

[2] GBD 2017 Causes of Death Collaborators. Global, regional, and national age - sex - specific mortality for 282 causes of death in 195 countries and territories, 1980 - 2017: a systematic analysis for the Global Burden of Disease Study 2017. Lancet 2018;392(10159):1736-88.

[3] Yusuf S, Hawken S, Ounpuu S, et al. Effect of potentially modifiable risk factors associated with myocardial infarction in 52 countries (the INTERHEART study): case - control study. Lancet 2004;364(9438):937-52.

[4] Sharma M, Ganguly NK. Premature coronary artery disease in Indians and its associated risk factors. Vasc Health Risk Manag 2005;1(3):217-25.

[5] Joshi P, Islam S, Pais P, et al. Risk factors for early myocardial infarction in South Asians compared with individuals in other countries. JAMA 2007;297(3):286-94.

[6] Prabhakaran D, Jeemon P, Roy A. Cardiovascular diseases in India: current epidemiology and future directions. Circulation 2016;133(16):1605-20.

[7] Anderson KM, Odell PM, Wilson PW, et al. Cardiovascular disease risk profiles. Am Heart J 1991;121(1 Pt 2):293-8.

[8] Arnett DK, Blumenthal RS, Albert MA, et al. 2019 ACC/AHA guideline on the primary prevention of cardiovascular disease: a report of the American College of Cardiology/American Heart Association Task Force on Clinical Practice Guidelines. Circulation 2019;140(11):e596-646.

[9] Ministry of Health and Family Welfare. Government of India. National Health Policy 2017. https:// www.nhp.gov.in/nhpfiles/national_health_policy_2017.p df
[10] Roth GA, Johnson C, Abajobir A, et al. Global, regional, and national burden of cardiovascular diseases for 10 causes, 1990 to 2015. J Am Coll Cardiol. 2017;70(1):1-25.

[11] Sacco RL, Roth GA, Reddy KS, et al. The heart of 25 by 25: achieving the goal of reducing global and regional premature deaths from cardiovascular diseases and stroke: a modeling study from the American Heart Association and World Heart Federation. Circulation 2016;133(23):e674-90.

[12] World Health Organization. Preventing chronic diseases: a vital investment: report WHO Global Organization 2005. https://apps.who.int/iris/handle/10665/43314.

[13] Hong YM. Atherosclerotic cardiovascular disease beginning in childhood. Korean Circ J 2010;40(1):1-9.

[14] Viner R, Macfarlane A. Health promotion. BMJ 2005;330(7490):527-9.

[15] Wagner J, Lacey K, Chyun D, et al. Development of a questionnaire to measure heart disease risk knowledge in people with diabetes: the Heart Disease Fact Questionnaire. Patient Educ Couns 2005;58(1):82-7.

[16] Umuerri EM. Heart disease: lifestyle, knowledge, and perception among young Nigerain adults. Int J Cardiovasc Acad 2019;5(4):134-40.

[17] Sadasivam K, Nagarajan PK, Ramraj B, et al. Cardiovascular disease risk factor knowledge assessment among medical students. Natl J Physiol Pharm Pharmacol 2016;6(3):251-7.

[18] Sattelmair J, Pertman J, Ding EL, et al. Dose response between physical activity and risk of coronary heart disease: a meta-analysis. Circulation 2011;124(7):78995.

[19] Yu E, Malik VS, Hu FB. Cardiovascular disease prevention by diet modification: JACC health promotion series. J Am Coll Cardiol 2018;72(8):914-26.

[20] Food safety and Standards Authority of India. Government of India. FSSAI Proposes Ten - point charter for food sold, supplied to school Children. Press release, Food Safety and Standards Authority of India. New Delhi $07 \quad$ Nov 2019. https://www.fssai.gov.in/upload/press_release/2020/0 9/5f589b491bc77Press_Release_Points_Food_School_09 _09_2020.pdf 